\title{
РАЗРАБОТКА СИСТЕМЫ УПРАВЛЕНИЯ СОЛНЕЧНЫМ ТРЕКЕРОМ НА БАЗЕ КОНТРОЛЛЕРА АРДУИНО
}

\author{
${ }^{1}$ Светлана Хан, \\ ${ }^{2}$ Нурбек Болатбеков
}

Республика Казахстан, Алматы, Алматинский университет энергетики и связи имени Г. Даукеева;

${ }^{1}$ профессор кафедры «Автоматизачия и управление»;

${ }_{2}^{2}$ магистрант специальности «Автоматизация и управление»

DOI: https://doi.org/10.31435/rsglobal_ws/30122019/6824

\section{ARTICLE INFO}

Received: 26 October 2019

Accepted: 21 December 2019

Published: 30 December 2019

\section{KEYWORDS}

renewable energy sources,

solar tracker,

control system,

Arduino.

\begin{abstract}
The panels that track the Sun using a tracker produce 30\% more energy (per day) than stationary. The article discusses the development of a solar tracker and its control system based on the Arduino controller. The results of experiments conducted on a stationary panel and a solar tracker are presented. A comparative analysis of the experimental results is presented.
\end{abstract}

Citation: Светлана Хан, Нурбек Болатбеков. (2019) Razrabotka Sistemy Upravleniya Solnechnym Trekerom na Baze Kontrollera Arduino. World Science. 12(52), Vol.1. doi: 10.31435/rsglobal_ws/30122019/6824

Copyright: (C) 2019 Светлана Хан, Нурбек Болатбеков. This is an open-access article distributed under the terms of the Creative Commons Attribution License (CC BY). The use, distribution or reproduction in other forums is permitted, provided the original author(s) or licensor are credited and that the original publication in this journal is cited, in accordance with accepted academic practice. No use, distribution or reproduction is permitted which does not comply with these terms.

Введение. Основные преимущества возобновляемых источников энергии неисчерпаемость и экологическая чистота. Их использование не изменяет энергетического баланса планеты. Эти качества и послужили причиной бурного развития возобновляемой энергетики. Возобновляемые источники энергии играют значительную роль в решении трех глобальных проблем, стоящих перед человечеством: энергетика, экология, продовольствие $[7,8,10]$.

Среди разнообразия экологически чистых источников энергии преобразование солнечного излучения в электричество представляется наиболее привлекательным и перспективным с точки зрения энергетических технологий будущего [6]. Полное количество солнечной энергии, поступающей на поверхность Земли за неделю, превышает энергию всех мировых запасов нефти, газа, угля и урана. Теоретический потенциал солнечной энергии, приходящий на Землю в течение года, превышает все извлекаемые запасы органического топлива в 10-20 раз [2].

Задача удовлетворения потребностей населения, промышленности и сельского хозяйства в электрической и тепловой энергии, особенно в регионах, удалённых от централизованных энергосетей, а также более глобальные проблемы энергообеспечения Казахстана в будущем и обеспечения экологической чистоты её территории, приводят к необходимости развития малой и нетрадиционной энергетики [5].

Актуальность развития солнечной энергетики в Республике Казахстан и, соответственно, необходимых технических средств - фотоэлектрических систем определяются следующими факторами $[1,3]$ : 
- Казахстан занимает территорию свыше 2,7 млн. км с благоприятными географическими и климатическими условиям для использования фотоэлектрических систем. Количество солнечных часов составляет 2200-3000 часов в год, а суммарная дневная радиация при реальных условиях облачности в республике составляет $3,8-5,2 \kappa \mathrm{\kappa T}^{*} ч / \mathrm{M}^{2}$. Для сравнения: среднее количество солнечных часов во Вьетнаме 2200 ч. (2,4-5,9 кВт*ч/кв.м.), Китае - 2500 ч. (4,5-6 кВт*ч/кв.м.), в Германии, Великобритании, Норвегии, Японии - менее 1000 ч в год.

- наличие большого числа объектов сельского хозяйства, ферм, поселков, кочевий, лишенных электроэнергии. Количество населенных пунктов, не имеющих электроснабжения, по данным журнала «Ветровая энергия в Казахстане» составляет порядка 5000.

- международные обязательства Казахстана по улучшению экологической обстановки и сокращению выбросов парниковых газов.

Проведенный аналитический анализ показал, что в настоящее время в связи с отсутствием на рынке ФЭС отечественного производства мощностью 5-10 кВт, для локальных целей электропотребления используются только ФЭС мощностью до 1 кВт. Но есть уже заказы на ФЭС мощностью 5-10 кВт и более. Однако в Республике Казахстан ФЭС такой мощности не производятся. В основном все ФЭС, функционирующие в Казахстане, это - либо зарубежные станции, которые достаточно дорогие, либо казахстанский эксклюзив, изготовленный в «гараже». Емкость данного рынка составляет от 20 до 30 МВт на сегодня [5].

В основном обычные (стационарные) солнечные панели работают с эффективностью $18-20 \%$ от получаемой энергии, это не совсем соответсвует потребностям в энергии [4]. Для того чтобы производить достаточное количество энергии нужно либо улучшить эффективность панелей или найти способ чтобы получать больше энергии от существующих панелей. Те панели, которые используются в повседневной жизни, находятся в фиксированном положении направленная на юг под углом 45 градусов. Этот подход чрезвычайно прост, но он не производит столько энергии, сколько мог бы быть.

Один из способов получении больше энергии от солнечной панели - это заставить ее отслеживать Солнце. Панели отслеживающие Солнце с помощью трекера производят на $30 \%$ больше энергии (в день), чем стационарная. Но не все готовы перейти на этот возобновляемый источник по следующим веским причинам. Во-первых, стоимость гелионавигационной установки выше, так как она требует движущей механической опоры для солнечной панели. Во-вторых, эта установка требует стабильного обслужвания и ухода, так как она будет подвергаться воздействию погодных условий на открытом воздухе круглый год [9].

Есть несколько различных типов солнечных трекеров (одноосевой, двухосевой, запланированный), а также способы отслеживания Солнца.

В целях экономии трекер можно установить только на одну ось Х или У. Обычно его устанавливают по оси $\mathrm{X}$, чтобы панель могла вращаться слева направо, а затем устанавливают панель на 45 градусов в сторону юга. Несмотря на то, что устраняют половину движущей части, одноосевой трекер вырабатывает достаточное количество энергии в отличии от стационарной панели.

В данном проекте разработан двухосевой трекер (рисунок 1). Он работает по двум осям (X и У), т.е. панель вращается на четыре стороны. Данный трекер является «активным»: управляется с помощью микроконтроллера Arduino, используя фотодатчики, чтобы найти самый яркий свет в любое время суток. Этот метод дает наилучшие результаты для выработки электроэнергии.

На рисунке 2 приведена принципиальная электрическая схема разработанного двухосевого солнечного трекера.

Для поворота панелей используются два сервопривода Tower Pro 9g SG90 (Servo1, Servo2), которые применяются в основном для управления небольшими легкими механизмами, угол поворота ограничен диапазоном от 0 до 180 градусов. 


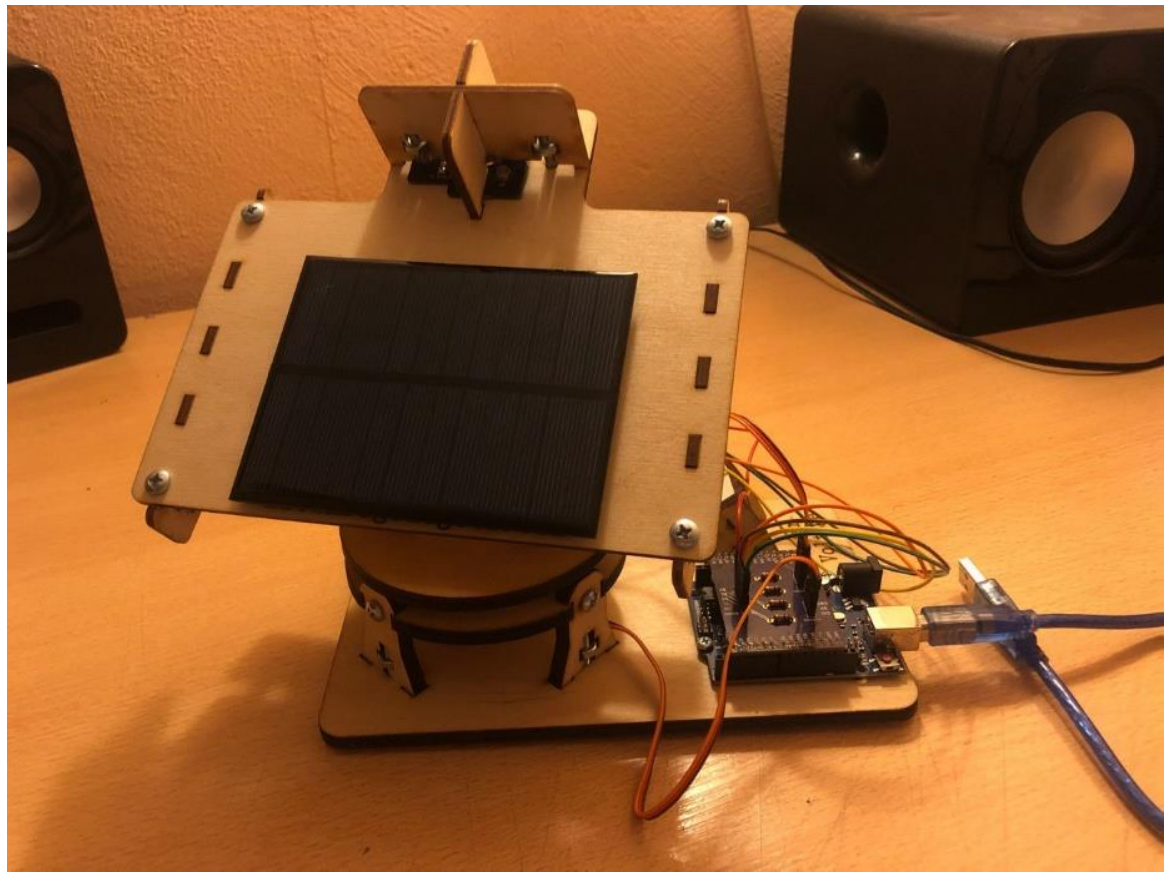

Рис. 1. Двухосевой солнечный трекер

В качестве датчиков используются четыре фоторезистора (LDR1-4). Они работают, изменяя значение сопротивления в зависимости от того, сколько света падает на них. Чем больше света, тем меньше величина сопротивления.

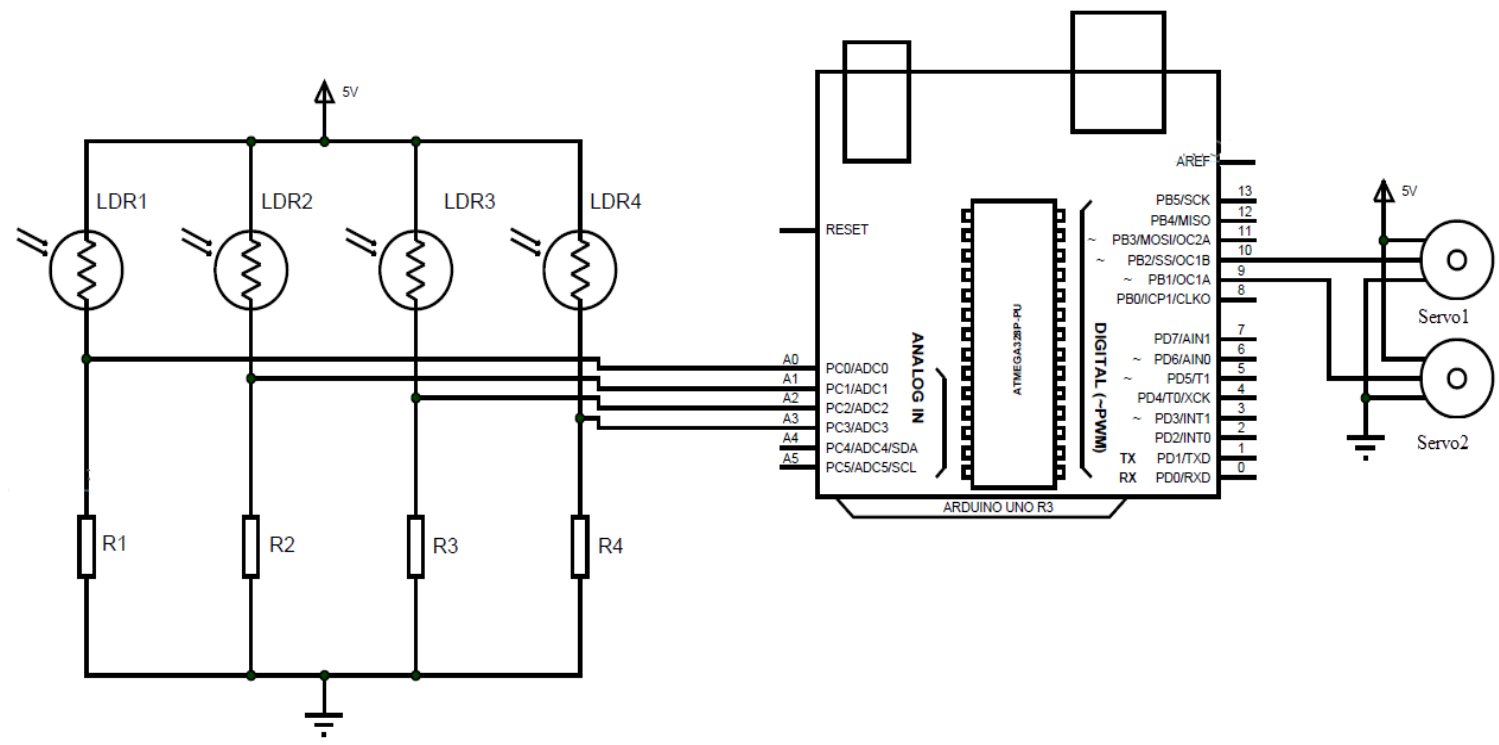

Рис. 2. Приниипиальная электрическая схема двухосевого трекера

\section{Проведение экспериментов.}

Исследования проводились на разработанной солнечной установке в двух режимах: в стационарном режиме и при движении солнечного трекера.

Время проведения экспериментов: ноябрь 2019 года, в течение 7 дней. Измерения проводились днем в интервале 8.00-19.00 часов.

Для каждой установки регистрировались мгновенная выходная мощность и ежедневно производимая энергия.

Исходя погодных условий, дни мониторинга были разделены на три класса:

- случай А: чистое небо;

- случай В: частично чистое небо;

- случай С: облачное небо. 
(A)

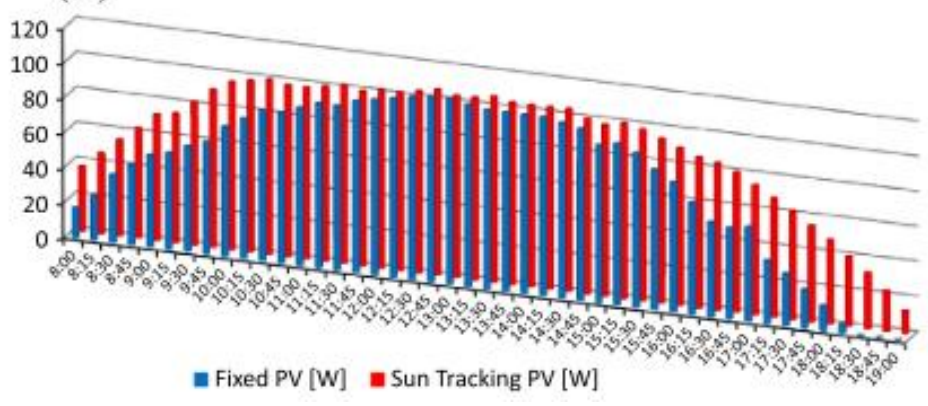

(B)

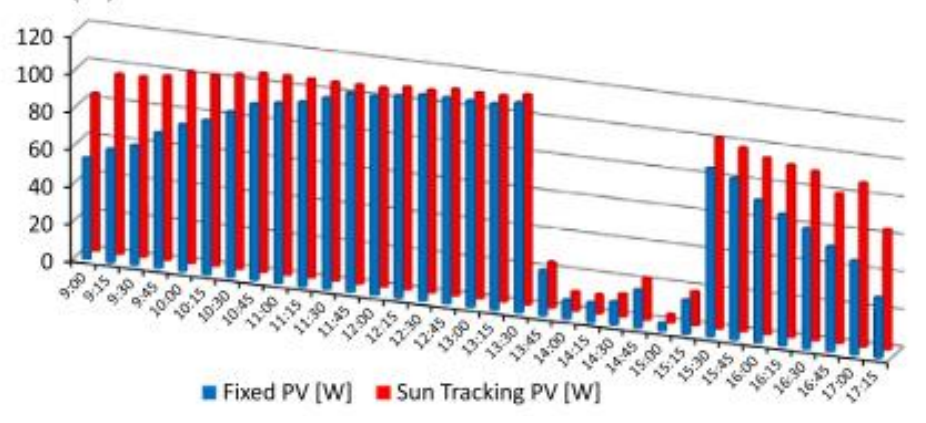

(C)

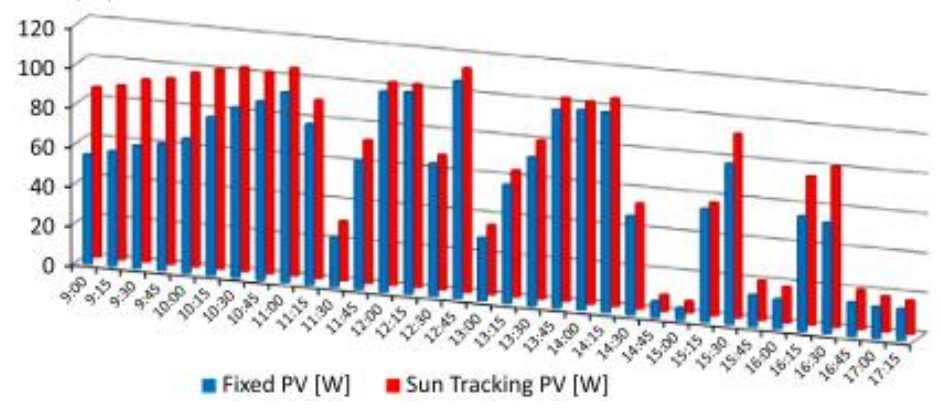

Pис. 3. Гистограммы мощности стационарной панели (Fixed PV) и панели на солнечном трекере (Sun Tracking PV)

Вывод. В случае А мощность регулярно меняется в течение дня, как показано на рисунке 3 (а). Как и ожидалось, панель с солнечным трекером значительно превосходит стационарную панель, особенно в начале и конце дня. В случае В действие солнечного трекера также выделяется в начале и конце дня, как показано на рисунке 3 (б). В случае С также очевидно преимущество солнечной панели, установленной на солнечном трекере.

\section{ЛИТЕРАТУРА}

1. Электроннный ресурс: http://1kz.biz/battery/artiklsfe.htm.

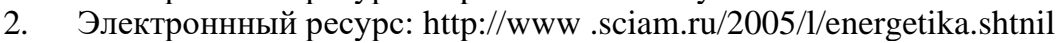

3. Электроннный pecypc: http://www.cnews.ru/news/top/index.shtml?2009/04/22/345049

4. Баранов Н.Н. Прямое преобразование энергии для автономной энергетики. Энергия: экономика, техника, экология.-2000.-№8.-c.23-34.

5. Газета «Деловой Казахстан» выпуск 08.10 .2008

6. Доводы в пользу использования энергии Солнца и других возобновляемых источников энергии. Возобновляемая энергия. -1998.- №4.-С.34.

7. Журнал Photon International №54, 2008 год.

8. Программа A1LTENER и другие программы ЕК по развитию возобновляемой энергии. Возобновляемая энергия. -2000.-№10-С6.

9. Рахимов К. Е., Хан С. Г., Стояк В. В. Система автоматизации гелио - навигационной установки для автоматической ориентации приемников солнечной энергии. Сб.труд. VIII междун. науч-практ. конф. Москва: РУДН, $2009-445 \mathrm{c}$.

10. Энергия будущего - возобновляемая энергия. Стратегия Европейского Союза в области возобновляемых источников энергии. Возобновляемая энергия. -2000.-№10.-С.14. 